\title{
Detection of complex hemoglobinopathies: recommendations on screening and DNA testing
}

\author{
E. Baysal \\ FRCP (London), Consultant Molecular Geneticist Head of Molecular Genetics, Senior Lecturer \\ Dubai Genetic \& Thalassemia Center, Dubai Health Authority, UAE
}

\begin{abstract}
The following recommendations should be taken into account during the evaluation and elucidation of the complex hemoglobinopathies: a) in complex hemoglobinopathies performing DNA studies on all family members might be essential; b) complex gene-gene interactions offer major diagnostic challenges both at the technical and clinical level; c) hematological \& DNA analyses must be run in parallel. Some cases may be straight forward but others may require indepth DNA work-up; d) co-inheritance of $\alpha$-thalassemia offers added challenge as it may affect phenotype significantly; e) sickle cell anemia (SS), co-inherited with $\alpha$-thal, can be a phenocopy of $\mathrm{S} \beta^{0}$-thal. The $\mathrm{HbA}_{2}$ increase can be mistaken for $\mathrm{S} \beta$-thal. DNA Sequencing is imperative; f) only a selected number of normal $\mathrm{MCV}, \mathrm{MCH}$, borderline $\mathrm{HbA}_{2}$ cases must be referred for DNA analysis. However, in certain cases, following hematological and family evaluation, the $\beta$ and $\delta$ genes may need to be sequenced; g) DNA Sequencing will increasingly become the method of choice for screening and DNA mutation analysis. However, new methods like MLPA-which analyzes gene dosage- must be used more commonly to rule out deletion mutants to avoid false negative sequencing results; $h$ ) these recommendations should be reviewed every 2-3 years reflecting new methods, new findings and new findings from ethnic groups.
\end{abstract}

\section{Introduction}

$\beta$-Thalassemia ( $\beta$-Thal) is an autosomal recessive disorder characterized by microcytosis, hypochromia and hemolytic anemia caused by

\footnotetext{
Correspondence: E. Baysal, FRCP (London), Consultant Molecular Geneticist Head of Molecular Genetics, Senior Lecturer, Dubai Genetic \& Thalassemia Center, Dubai Health Authority, UAE.
}

Key words: haemoglobinopathies, screening.

(C) Copyright E. Baysal, 2011

Licensee PAGEPress, Italy

Thalassemia Reports; 1(s2):e31

doi:10.4081/thal.2011.s2.e31

This article is distributed under the terms of the Creative Commons Attribution Noncommercial License (by-nc 3.0) which permits any noncommercial use, distribution, and reproduction in any medium, provided the original author(s) and source are credited.

Parts of this work were presented at the "12th International Conference on Thalassemia and Hemoglobinopathies", Antalya (Turkey), 11-14 May 2011. either a decrease $\left(\beta^{+}\right)$or a total absence $\left(\beta^{0}\right)$ of the production of $\beta$ globin chains in the hemoglobin molecule. The highest incidences are reported in Cyprus (18\%) (Baysal et al., 1992) ${ }^{1}$ and Sardinia (12\%) (Cao and Galanello 2002; Cao et al., 1991, 1996) ${ }^{5,6,7}$ and South East Asia (Fucharoen, 2002). ${ }^{12}$ The high gene frequency of $\beta$-thalassemias in these regions is most likely related to the selective pressure from malaria (Flint et al. 1998). ${ }^{11}$ This distribution is quite similar to that of endemic Plasmodium falciparum malaria. Thalassemia is found almost everywhere in the world albeit it is most common in the Mediterranean Basin, North Africa, the Middle East, Indian Subcontinent and Southeast Asia (Thein, 1998). ${ }^{15}$ However, because of population migration and, in a limited part, the slave trade, $\beta$-thalassemia is now also common in Northern Europe, North and South America, the Caribbean, and Australasia.

It is estimated that more than 300 million people in the world carry either the $\alpha$ - or $\beta$-thalassemia gene. While $\alpha$-thalassemia appears to be common in Southeast Asia, India, and the South Pacific, $\beta$-thal is the most common genetic disorder in the Mediterranean countries with frequencies as high as $15-20 \%$ in some island populations such as Cyprus and Sardinia. It constitutes a major public health problem in most Mediterranean countries. Thus far, more than $250 \beta$-thalassemia mutations have been reported worldwide, each population having its own spectrum of alleles (Huisman, Carver, Baysal, 1997). ${ }^{14}$

Common hemoglobinopathies such as $\beta$-thal, $\alpha$-thal, HPFH, $\delta \beta$-thal and abnormal Hbs (HbE, S, C, Lepore, D-Punjab, 0-Arab) can be detected easily. Their accurate identification can provide valuable diagnostic and prognostic options for clinicians and for couples who may have to consider family planning.

The diagnosis of hemoglobinopathies has become an increasing challenge in the multinational countries such as Australia, USA, Canada as well as in Europe and the Gulf Countries. This is well exemplified by Dubai which is home to 202 different nationalities (latest figures), hence the propensity for significantly enriched thalassemia gene pool coupled with high degree of consanguinity. In an attempt to curb the hemoglobinopathy problem, the National Premarital Screening Program was rendered mandatory in Dubai in 2006 for all nationalities and the Prenatal Diagnosis Program has been underway successfully since 2005. (Baysal, E., 2005; Baysal et al., 2007)..$^{3,4}$ These preventive programs were imperative as hemoglobinopathies are a major public health concern in the UAE. Dubai is arguably the most heterogeneous hemoglobinopathy nation in the world with $55 \beta$ globin gene defects reported to date (Baysal, E. 2001, 2007).2,4

It is anticipated that various complex hemoglobinopathies with extensive heterogeneity in genotype and variable phenotype will emerge from such admixture of genes in a small nation where first cousin marriage among the indigenous population is a norm and not an exception. In addition, $\alpha$-thal and $\beta$-thal interactions occur due to relatively high frequencies of $\alpha$ globin and $\beta$ globin gene defects; $50 \%$ and 8.3\%, respectively (El Kalla and Baysal, 1998; Baysal, 2005). ${ }^{3,9}$ This makes clinical diagnosis and laboratory evaluation much more challenging in a young nation where $26 \%$ of the population is below age 15 and $71 \%$ is between $15-64$. 
The laboratory diagnoses of hemoglobinopathies are often made with certain assumptions: a) Variation in the phenotype could be a reflection of interplay between different abnormal globin genes $(\alpha, \beta$, $\gamma, \delta)$; b) Same genotypes may have different phenotypes in different geographical areas thus denoting the role of environment as a modulator; c) Complex genotypes occur rarely so no concrete conclusions must be drawn from only a few examples.

Here we provide guidance to clinicians, counsellors and healthcare providers on complex hemoglobinopathies only. Several real case scenarios and various algorithms will be discussed to reach correct diagnoses. Comparison from different laboratories highlight the importance of appropriate lab assessment and interpretation especially with reference to different normal ranges for $\mathrm{MCV}, \mathrm{MCH}, \mathrm{HbA}_{2}$ adopted in different labs.

One of the most debated issues in the diagnosis of complex hemoglobinopathies is the genotypes caused by more than one genotype. Some of these are also associated with atypical $\beta$-thalassemia carriers. The classical phenotype of heterozygous $\beta$-thalassemia, essentially characterized by reduced MCV and $\mathrm{MCH}$ and increased $\mathrm{HbA}_{2}$, may be modified by several genetic factors thus resulting in potential problems in carrier diagnosis and identification. The most common forms of atypical carriers with corresponding genotypes are shown in Table 1.

The category of atypical $\beta$-thal carriers include $\beta$-thal heterozygote with an unusually severe hematological and clinical phenotype.

The co-inheritance of heterozygous $\beta$-thal with homozygous $\alpha+$-thal $(-\alpha /-\alpha)$ or heterozygous $\alpha 0$-thal $(--/ \alpha \alpha)$ has a significant effect on the red cell indices particularly MCV and MCH which may be normalized. The effect of interacting silent / mild heterozygous $\alpha+$-thal $(-\alpha / \alpha \alpha)$ is usually less evident. It is important to note that the $\mathrm{HbA}_{2}$ levels in these double heterozygotes remain elevated within the range of $\beta$-thal carriers which makes it highly significant practically thus making it imperative to carry out the $\mathrm{HbA}_{2}$ determination in screening programs. This will in turn enable correct diagnosis of double heterozygotes for $\beta$-thal and $\alpha$-thal. However, a primary screening involving $\mathrm{CBC}$ and $\mathrm{HbA}_{2}$ determination only, reduced MCV and MCH may not be adequate for the correct identification of individuals who are double heterozygotes.

Some $\beta$-thal heterozygotes have normal or borderline $\mathrm{HbA}_{2}$ levels but $\mathrm{MCV}$ and MCH within the typical carrier range. Such carriers include heterozygotes for some mild mutations such as IVS-I-6 $(\mathrm{T} \rightarrow \mathrm{C})$, double heterozygotes for $\mathrm{Hb}$ Knossos and $\delta$-thal, double heterozygotes for the $\delta$ - and $\beta$-thalassemia both in cis and in trans, carriers of Corfu $\delta \beta$-thalassemia and rare carriers of $\varepsilon \gamma \delta \beta$-thalassemia. The latter involves large deletions (e.g.: English, Dutch, Spanish types) which removes all the $\beta$-like genes but spares the $\beta$-globin gene. These determinants can be differentiated from each other by carrying out family studies or through laborious globin chain synthesis or globin gene analysis.

Another group of atypical carriers leading to complex hemoglobinopathies and causing dilemmas in diagnosis are those characterized by very mild or silent $\beta$-thal mutations (Huisman et al., 1997). ${ }^{14}$ These mutations are characterized by high residual synthesis of $\beta$ globin chain output. Generally the $\mathrm{CBC}$ and $\mathrm{HbA}_{2}$ are normal or borderline. Atypical carriers also include carriers of triplicated $\alpha$-globin genes. In these individuals, the level of $\alpha$ chains could be equivalent to those seen in very mild $\beta$-thal heterozygotes. Usually silent $\beta$-thals are identified and diagnosed retrospectively whereby a patient is characterized with mild $\beta$-thal intermedia which prompt the molecular analysis of the parents. If silent $\beta$-thal is suspected based on $\mathrm{CBC}$ and borderline $\mathrm{HbA}_{2}$ levels, it is usually recommended that either globin chain studies or the mutational analysis of the $\beta$-gene promoter region are performed, consisting of regulatory motifs or sequences involved in critical expression of the $\beta$-gene downstream. Due to their silent phenotype, most of the time these determinants will be missed during general population screening programs. However this will be a concern prospectively as homozygosity for these mild or silent $\beta$-thal alleles or even compound heterozygosities for mild and severe $\beta$-thal mutations usually results in moderate to moderately severe forms of $\beta$-thal intermedia.

Although rare, sometimes a combination of $\alpha$-, $\beta$ - and $\delta$-thalassemia gene defects may also be co-inherited (Galanello et al., 1988). ${ }^{13}$ Often they lead to a silent phenotype that may be problematic in reaching a correct diagnosis in population screening. Often these gene defects can be elucidated through molecular analysis.

Occasionally, $\beta$-thal carriers could have significant clinical phenotype. Co-inheritance of $\beta$-thal with triplicated $\alpha$-globin gene $(\alpha \alpha \alpha / \alpha \alpha$ or $\alpha \alpha \alpha / \alpha \alpha \alpha$ ) generally results in $\beta$-thal intermedia phenotype (Fallah et al., 2009)..$^{10}$ However, co-inheritance of $\beta$-thal heterozygosity with $\mathrm{HbH}$ disease (--/- $\alpha$ or $\alpha \mathrm{T} \alpha / \alpha \mathrm{T} \alpha)$ often results in moderately severe phenotype with typical $\mathrm{Hb} 8-10 \mathrm{~g} / \mathrm{dL}$, marked microcytosis $(\mathrm{MCV}<60 \mathrm{fl})$ and hypochromia ( $\mathrm{MCH}<19 \mathrm{pg})$. In these conditions the $\mathrm{HbA}_{2}$ levels are usually elevated equivalent to $\beta$-thal carrier status and $\mathrm{HbH}$ inclusions are usually absent.

Mutations affecting the Exon 3 region of the $\beta$-globin gene often results in dominant $\beta$-thal characterized by accumulation of hyperunstable hemoglobin variants. These precipitate inside the immature red cells and erythroid bone marrow precursors giving rise to a marked clinical severity, often requiring treatment. The abnormal chains are unable to form functional hemoglobin tetramers and do not carry oxygen. This results in ineffective erythropoiesis and eventually in thalassemia intermediate with elevated $\mathrm{HbA}_{2}$ and unbalanced $\alpha / \beta$ ratio. Due to early precipitation in red cell precursors, the $\beta$-chain variant is generally not detectable in mature red cells. Because only one single mutational event results in such a dramatic phenotype in a heterozygous state, these forms of hemoglobin disorders are also known as dominant $\beta$-thalassemia.

Complex hemoglobinopathies often involve more than one simple genotype. However, in all cases, routine hematology \& DNA testing should detect heterozygotes, homozygotes and compound heterozygotes for $\alpha$ thal, $\beta$ thal, HPFH and high Hb F thalassemias as well as abnormal hemoglobins such as $\mathrm{Hb} \mathrm{S}, \mathrm{Hb}$ E, Hb C, Hb D-Punjab, Hb OArab and $\mathrm{Hb}$ Lepore. Rare genotypes including deletional HPFH, $\varepsilon \gamma \delta \beta$ Thal, $\delta \beta$-Thal, as well as those involving LCR (HSS 2-4) could only be elucidated in highly specialized laboratories through gene analysis.

\section{Table 1.}

1. Normal MCV is associated with co-inheritance of -thal

2. Borderline /normal $\mathrm{HbA}_{2}$ is associated with

a. Silent / mild $\beta$-thal alleles

b. Co-inheritance of $\delta$-thal

c. $\varepsilon \gamma \delta \beta$-thalassemia

d. Corfu $\delta \beta$-thalassemia

3. Normal MCV, $\mathrm{MCH}$ and $\mathrm{HbA}_{2}$ (a.k.a. Silent carrier) is associated with

a. Very mild/silent alleles

b. Triplicated $\alpha$-globin gene arrangement

4. Significant clinical phenotype is associated with

a. Co-inheritance of $\alpha$-thal determinants

b. Triplicated $\alpha$-globin genes, $\mathrm{HbH}$ disease genotype $(--/-\alpha)$ $\left(\alpha^{\mathrm{T}} \alpha / \alpha^{\mathrm{T}} \alpha\right)$

c. Hyperunstable globin chains (Dominant $\beta$-thal)

\section{References}

1. Baysal E, Indrak K, Bozkurt G, et al. The $\beta$-thalassemia mutations in the population of Cyprus. British Journal of Haematology 1992;81:607-609.

2. Baysal E, Hemoglobinopathies in the United Arab Emirates, 
Advances in Hemoglobinopathies Research, Hemoglobin 2001;25, 247-253.

3. Baysal E. Molecular heterogeneity of $\beta$-Thalassemia in the United Arab Emirates. Community Genetics, 2001;8:35-39.

4. Baysal E, Yousef I, Zeinali M, et al. Review: molecular basis of hemoglobinopathies in the UAE: implications for prenatal diagnosis andprevention programs, emirates medical journal, 2007;25:721.

5. Cao A, Galanello R. Effect of Consanguinity on Screening for Thalassemia. NEJM 2002;347:1200-1202.

6. Cao A, Rosatelli MC, Galanello R. Population-based genetic screening. Curr Opin Genet Dev. 1991;1:48-53.

7. Cao A, Rosatelli MC, Galanello R. Control of $\beta$-thalassaemia by carrier screening, genetic counselling and prenatal diagnosis: the Sardinian experience. Ciba Found Symp. 1996;197:137-51.

8. Cao, A. Carrier screening and genetic counselling in $\beta$-thalassemia. Int J Hematol. 2002;76:105-13.

9. El-Kalla S, Baysal E. $\alpha$-thalassemia in the United Arab Emirates,
Acta Haematol, 1998;100:1,49-53.

10. Fallah MS, Aleyasin SA, Ebrahimi A, et al. Molecular characterization of thalassemia intermedia, due to co-inheritance of homozygous $\alpha$ triplication and IVS-I- $5 \beta$-thalassemia.

11. Flint J, Harding RM, Boyce AJ, Clegg JB. The population genetics of the haemoglobinopathies. Baillieres Clin Haematol. 1998;11:1-51.

12. Fucharoen S, Fucharoen G, Sanchaisuriya K, Pengjam Y. Molecular analysis of a Thai $\beta$-thalassaemia heterozygote with normal haemoglobin A2 level: implication for population screening. Ann Clin Biochem. 2002;39:44-9.

13. Galanello R, Paglietti ME, Addis M, et al. Pitfalls in genetic counselling for $\beta$-thalassemia: an individual with four different thalssemia mutations. Clinical Genetics 1988;33:151-155.

14. Huisman THJ, Carver, MFH, Baysal, E. A syllabus of thalassemia mutations (1997) The sickle cell anemia foundation, Augusta, GA, USA, (http://globin.cse.psu.edu).

15. Thein S.L. $\beta$-Thalassemia. Bailliere's Clin Haematol. 1998;11:91126. 